\title{
Lack of association between diabetic nephropathy and human leukocyte antigen type 2 (HLA II-DQ1) in patients with type 2 diabetes mellitus in west of Iran
}

\author{
Mahsa Mohammadi ${ }^{1}{ }^{\circledR}$, Mohsen Rajabnia $^{2}{ }^{\circledR}$, Mohammad Saad Forghani $^{3^{*}(\odot)}$, Khaled Rahmani ${ }^{2,4}{ }^{\circledR}$, \\ Mohammad Bahadoram ${ }^{5,6} \mathbb{D}$ \\ ${ }^{1}$ Student Research Committee, Kurdistan University of Medical Sciences, Sanandaj, Iran \\ ${ }^{2}$ Liver and Digestive Research Center, Research Institute for Health Development, Kurdistan University of Medical Sciences, Sanandaj, Iran \\ ${ }^{3}$ Department of Internal Medicine, Faculty of Medicine, Kurdistan University of Medical Sciences, Sanandaj, Iran \\ ${ }^{4}$ Social Determinants of Health Research Center, Kurdistan University of Medical Sciences, Sanandaj, Iran \\ ${ }^{5}$ Chronic Renal Failure Research Center, Department of Internal Medicine, Faculty of Medicine, Ahvaz Jundishapur University of Medical Sciences, \\ Ahvaz, Iran \\ ${ }^{6}$ Thalassemia and Hemoglobinopathy Research Center, Research Institute of Health, Ahvaz Jundishapur University of Medical Sciences, Ahvaz, Iran
}

\section{A R T I C L E I N F O}

Article Type:

Original

\section{Article History:}

Received: 7 May 2020

Accepted: 26 July 2020

Published online: 18 August 2020

\section{Keywords:}

Type 2 diabetes mellitus

Diabetic nephropathy

Diabetic kidney disease

Human genome

\begin{abstract}
A B S T R A C T
Introduction: Diabetic nephropathy (diabetic kidney disease) is one of the microvascular complications of diabetes mellitus. The human leukocyte antigen (HLA) is a group of genes that is related to autoimmune diseases, infections and inflammation. Studies regarding the association of type 2diabetes and HLA-II are negligible.

Objectives: The aim of this study is to determinate association between diabetic nephropathy and HLA II-DQ1 in diabetes type 2 patients.

Patients and Methods: In this study, 120 diabetes type 2 patients were divided into two groups of diabetic nephropathy (case group) and without diabetic nephropathy (control group). Blood samples were taken and DNA was isolated. Asymmetric polymerase chain reaction (PCR) was used to amplify the HLA II-DQ1 exon 2 and exon 3. PCR products were hybridized and labeled with probes on the chip. Determination of HLAII-DQ1 gene typing was conducted by scanning hybrid products and analyzed with PerkinElmer ScanArray software.

Results: The results of chi-square test showed no significant difference between expression levels of HLA in the two groups $(P<0.05)$.

Conclusion: There was no significant difference between expression levels of HLA in two groups of patients. Various factors such as demographic characteristics, lifestyle, geographic region, and race are the factors influencing the relationship between diabetic nephropathy and DQ1-HLA II. Since this study is conducted in one region and one race and with limited population, it is suggested that future studies should be considered and the association between the mentioned variables with HLA should be considered.
\end{abstract}

\section{Implication for health policy/practice/research/medical education:}

The association between diabetic nephropathy and human leukocyte antigen type 2 (HLA II-DQ1) in patients with type 2 diabetes mellitus can be a risk factor for diabetic kidney disease.

Please cite this paper as: Mohammadi M, Rajabnia M, Forghani MS, Rahmani K, Bahadoram M. Lack of association between diabetic nephropathy and human leukocyte antigen type 2 (HLA II-DQ1) in patients with type 2 diabetes mellitus in west of Iran. J Renal Inj Prev. 2021; 10(4): e34. doi: 10.34172/jrip.2021.34.

\section{Introduction}

Diabetes mellitus is a distinct group of metabolic disorders identified with chronic hyperglycemia and disorder of carbohydrates, lipids, and protein metabolism due to insufficiency of the secretion or function of the insulin, which ultimately leads to long-term complications in various systems of the body (1). The prevalence of diabetes has increased dramatically over the past two decades, from around 30 million in 1985 to 382 million in 2013, and according to the reports, by 2035, the global 
prevalence of this disease will reach 592 million (2).

Complications associated with diabetes can be divided into two vascular and non-vascular categories that are similar in type 1 and type 2 diabetes (T2DM). Vascular complications of diabetes are classified into macrovascular groups (including cerebrovascular disease, coronary artery disease and peripheral vascular disease) and micro-vascular (including diabetic nephropathy, diabetic retinopathy and diabetic neuropathy) $(3,4)$. The most common cause of renal failure in the United States and Europe and in many developing countries is diabetic nephropathy $(5,6)$. Asian people with type 2 diabetes have a higher incidence of nephropathy $(7,8)$. About $43 \%$ of type 2 diabetes patients suffer from chronic renal disease, of which the prevalence of chronic renal disease is $61 \%$ among patients aged 65 years and older (9). Several causes have been reported for diabetic nephropathy(diabetic kidney disease), including hyperglycemia, hypertension, inflammation, smoking, and dyslipidemia (10,11). Additionally, familial clustering indicates the role of genetic in pathogenesis of diabetic nephropathy (12).

The human leukocyte antigen (HLA) is a group of genes, which has been mostly studied with regard to its association with autoimmune diseases, infections and inflammation. The association of type 1 diabetes and HLA class 2 has been reported in various studies $(13,14)$. However, the number of studies regarding the association of type 2 diabetes and HLA class 2 are scarce. Studies have reported various results on the association between type 1 diabetes and HLA class II. For example, in the study of Chowdhury et al in England, no relationship was reported between diabetic nephropathy and HLA class II (15). Additionally in the study by Ražanskaitè-Virbickienè et al in Lithuania, HLA-DRB1*03 was reported as a risk factor for diabetic nephropathy $(P=0.021)(13)$ and in the study of Cordovado et al in the United States, HLA-DRB1*04 was introduced as a protective agent against diabetic nephropathy $(P=0.001)(14)$. Accordingly, in a study conducted by $\mathrm{Ma}$ et al in China, the relationship between type 2 diabetes and HLA-DQA1 and HLA-DQB1 was investigated, which showed a significant relationship was reported compared to the healthy subjects (control group) $(P<0.01)(16)$.

Considering the high prevalence of type 2 diabetes and also the risk of diabetic nephropathy as an important complication and an effective factor on the morbidity and mortality of this disease, conducting studies is necessary to better understanding the pathogenesis of the disease. Since HLA II-DQ1 has been shown to be effective in various diseases and has contributed to its role in diabetic nephropathy in type 2 diabetes, as well as the racial differences in the genetics of patients, we therefore aimed to determine the relationship between HLA II-DQ1 and diabetic nephropathy in type 2 diabetes patients in Kurdistan province, west of Iran.

\section{Objectives}

The aim of this study is to determinate relationship between diabetic nephropathy and human leukocyte antigen type 2 (HLA II-DQ1) in type 2 diabetes mellitus patients.

\section{Patients and Methods}

Patients

In this study, patients with type 2 diabetes who referred to the Tohid hospital of Sanandaj (affiliated to Kurdistan University of Medical Sciences) based on the 2017 American Diabetic Association diagnostic criteria (17) were selected as the study population. These patients entered the study based on the inclusion and exclusion criteria. In this study, exclusion criteria were; 1 ) secondary diabetes due to specific cause (e.g, Cushing's syndrome or chronic pancreatitis) 2) type 1 diabetes, 3) patient dissatisfaction. Finally, 120 patients were enrolled in the study. Patients were divided into 2 groups of type 2 diabetes mellitus with diabetic nephropathy as the case group and the type 2 diabetic group without diabetic nephropathy (based on protein excretion in 24-hour urine) as the control group. The non-diabetic nephropathy group included patients with a history of at least 10 years of type 2 diabetes mellitus without albuminuria (24hour urinary albumin $<30 \mathrm{mg}$ ). Patients with diabetic nephropathy included type 2 diabetes patients with microalbuminuria (24-hour urinary albumin of 30-299 $\mathrm{mg}$ ) or macroalbuminuria (24-hour urinary albumin $\geq 300 \mathrm{mg}$ ). Albuminuria was confirmed after rule out of other causes such as urinary tract infection, hematuria, nephritis, and other causes of transient proteinuria and in at least two trials with intervals of 3 to 6 months. Finally, 60 patients in the case group and 60 patients in the control group were placed. Matching for age and duration was performed in the form of group matching. In this way, mean age and mean duration in the two groups of case and control were approximately equal. For gender, individual matching was performed.

\section{Intervention and biochemical measurements}

After explaining all of the stages of the study for the patients and getting informed written consent from them, $2 \mathrm{cc}$ peripheral blood containing ethylenediaminetetraacetic acid (EDTA) anticoagulant was collected from each individual and DNA was extracted based on column method using blood genomic DNA extraction kit of Favorgen company (China) with catalog number FABGK001 and the quality and the quantity of DNA was determined using DeNovix DS-11 FX spectrophotometer.

Then, using the DQ low-resolution kit of Olerup Company, the DQA1 and DQB1 alleles were reproduced in the presence of Master Mix and Taq DNA polymerase in the T100 thermal cycler (Bio-Rad, USA). The polymerase chain reaction (PCR) products were electrophoresed on 
2\% agarose gels, stained with Ethidium bromide and visualized under UV light by gel documentation system. Finally, the obtained image was analyzed using SCORE ${ }^{\mathrm{TM}}$ software (Olerup SSP company) version 5.00.80.02T and the presence and absence of alleles were investigated.

\section{Data analysis}

Data analysis was performed using Stata version 13 software. To analyze the data, descriptive statistics including mean and standard deviation were used to describe the quantitative variables and frequency and percentage were used to describe the qualitative variables. To compare the clinical and biochemical variables in both groups, independent $t$ test and chi-square test were used. The level of significance was $P<0.05$.

\section{Results}

The mean and standard deviation of biochemical and clinical features of the patients are presented in Table 1. In addition, the frequency and percentage of biochemical and clinical features of the patients are reported in Table 2. This table compares the mean quantitative parameters and the frequency distribution of qualitative parameters evaluated in diabetic nephropathy patients and patients without nephropathy. Independent t-test showed that systolic blood pressure, diastolic blood pressure and low-density lipoprotein (LDL-C) mean values were appreciably different in both groups $(P<0.05)$. The mean of systolic blood pressure, diastolic blood pressure and LDL-C in patients with nephropathy was appreciably higher than in patients without retinopathy. Additionally, the frequency distribution of hypertension in the two groups was appreciably different $(P<0.05)$. While 52 $(86.7 \%)$ of patients with hypertension were in the group of patients with nephropathy. Table 3 and Figure 1 show the frequency of different levels of HLA in the two patient groups. According to the results of this study, alleles of HLA-DQA ${ }^{*} 0401$ and HLA-DQA ${ }^{*} 0301$ and HLADQB1*0201 were $15 \%, 13.3 \%$ and $13.3 \%$ respectively

Table 1. Demographic findings of the studied patients

\begin{tabular}{lc}
\hline Variable & Studied population (120 cases) \\
\hline Age (year) & $62.73 \pm 9.60$ \\
Gender & $60(50 \%)$ \\
$\quad$ Female & $60(50 \%)$ \\
$\quad$ Male & $50.56 \pm 6.4$ \\
Age of onset (year) & $12.25 \pm 5.12$ \\
Duration of the disease (year) & $29.26 \pm 2.49$ \\
Body mass index (kg/m ${ }^{2)}$ & $87(72.5 \%)$ \\
Hypertension & $90(75 \%)$ \\
Insulin therapy & $19(16 \%)$ \\
Oral agent therapy & $11(9 \%)$ \\
Combination therapy & \\
(Insulin and Oral agent) &
\end{tabular}

in type 2 diabetes patients and diabetic nephropathy since in the non-diabetic nephropathy group, the highest rates were $13.3 \%, 11.7 \%$ and $11.7 \%$, for alleles of HLA-DQA $1 * 0301$ and HLA-DQB1*0201 and HLADQB1*0501 respectively. The findings of this study showed no significant difference between different levels of HLA in the two groups $(P<0.05)$.

\section{Discussion}

In this study, findings showed that the mean body mass index (BMI) in the patients was $29.26 \pm 2.49 \mathrm{~kg} / \mathrm{m}^{2}$ and indicates overweight, which was consistent with the studied by Wei et al (18), Zhou et al (19) and Saleem et al (20). Obesity is very common in type 2 diabetes ( $\geq 80 \%$ of patients are obese), also it is thought to be part of the pathogenic process. Therefore, if obese patients lose weight, they will reduce the complications of diabetes, while in other studies $(21,22)$ weight loss up to $5-10 \%$ in overweight patients reduces the risk of diabetes and improves glucose control.

The results showed that hypertension was appreciably different between the two groups and the number of people with hypertension was higher in the group of patients with nephropathy, which was consistent with the study by Aghamohammadzadeh et al (23). In this study, less than $50 \%$ of patients were hypertensive which was consistent with the study by Safaei et al (24). There are various reasons for high blood pressure in patients of this study, which for example, age and gender can be mentioned; therefore, blood pressure is lower in younger people. Studies such as Duggirala et al reported that for every 10 years increase in age, blood pressure increases for 0.83 times (25).

Our findings did not show significant association between HbAlc (glycated haemoglobin) in diabetic nephropathy and non-diabetic nephropathy patients, which is similar to the study of Farahandi et al (26). As well, in the present study, the mean of HbAlc was $9.94 \pm$ $1.28 \%$ which was higher than the mean reported in the study of Rahimi et al $(8.7 \pm 1.9 \%)$ (27). Higher mentioned mean for $\mathrm{HbAlc}$ in the present study can be due to the type of diet and lifestyle, as in Glasgow et al, HbAlc was attributed to factors such as diet and exercise (28).

The findings of this study showed that there was no significant difference between different levels of HLA in the two groups. In the study of Quiroz-Mercado et al in Mexico, a significant association was found between diabetic retinopathy and HLA-DRB1*1406 in type 2 diabetic patients (29). The study by Marzban et al showed a significant relationship between diabetic peripheral neuropathy and HLA-DRB1*10 and HLA-DRB1*12 in type 2 diabetes patients (30). In a study conducted by $\mathrm{Ma}$ et al in China with the aim of determining the association between type 2 diabetes mellitus and HLA-DQA1 and HLA-DQB1, a significant correlation with the control 
Table 2. Clinical and biochemical parameters of the two groups

\begin{tabular}{|c|c|c|c|}
\hline \multirow[b]{2}{*}{ Variables } & \multicolumn{2}{|c|}{ Groups } & \multirow[b]{2}{*}{$P$ value } \\
\hline & $\begin{array}{c}\text { Patients with T2DM without diabetic } \\
\text { nephropathy (60 cases) }\end{array}$ & $\begin{array}{c}\text { Patients with T2DM and diabetic } \\
\text { nephropathy (60 cases) }\end{array}$ & \\
\hline Age (y) & $62.41 \pm 9.67$ & $63.05 \pm 9.61$ & 0.72 \\
\hline \multicolumn{4}{|l|}{ Gender } \\
\hline Female & $30(50 \%)$ & $30(50 \%)$ & \multirow{2}{*}{0.57} \\
\hline Male & $30(50 \%)$ & $30(50 \%)$ & \\
\hline Age of Onset (y) & $51.08 \pm 6.03$ & $50.05 \pm 6.77$ & 0.38 \\
\hline Duration of disease $(\mathrm{y})$ & $11.53 \pm 5.6$ & $12.98 \pm 4.51$ & 0.12 \\
\hline $\mathrm{BMI}\left(\mathrm{kg} / \mathrm{m}^{2}\right)$ & $28.98 \pm 2.56$ & $29.55 \pm 2.41$ & 0.21 \\
\hline Hypertension & $35(58.33 \%)$ & $53(86.66 \%)$ & $0.001^{*}$ \\
\hline Systolic BP (mm Hg) & $126.5 \pm 8.82$ & $131.28 \pm 11.39$ & $0.01^{*}$ \\
\hline Diastolic BP (mm Hg) & $81.06 \pm 7.61$ & $84.4 \pm 9.63$ & $0.03^{*}$ \\
\hline Insulin therapy & 46 (76.66\%) & $44(73.33 \%)$ & 0.6 \\
\hline Oral agent therapy & $10(16.66 \%)$ & $9(15 \%)$ & 0.8 \\
\hline Combination therapy (Insulin and oral agent) & $6(10 \%)$ & $5(8.33 \%)$ & 0.5 \\
\hline $\mathrm{HbA} 1 \mathrm{c}(\%)$ & $9.77 \pm 1.25$ & $10.11 \pm 1.3$ & 0.14 \\
\hline $\mathrm{FPG}(\mathrm{mg} / \mathrm{dL})$ & $186.2 \pm 34.52$ & $189.45 \pm 34.23$ & 0.6 \\
\hline TG $(\mathrm{mg} / \mathrm{dL})$ & $280.61 \pm 81.4$ & $263.85 \pm 84.27$ & 0.27 \\
\hline $\mathrm{HDL}(\mathrm{mg} / \mathrm{dL})$ & $38 \pm 5.06$ & $38.26 \pm 5.46$ & 0.78 \\
\hline $\mathrm{LDL}(\mathrm{mg} / \mathrm{dL})$ & $124.86 \pm 31.01$ & $151 \pm 29.41$ & $0.001^{*}$ \\
\hline $\mathrm{GFR}(\mathrm{mL} / \mathrm{min})$ & $46.3 \pm 14.28$ & $42.9 \pm 14.96$ & 0.2 \\
\hline
\end{tabular}

BMI: Body mass index, BP: blood pressure, FPG: fasting plasma glucose, TG: triglyceride, HDL: high density lipoprotein, LDL: low density lipoprotein, GFR: glomerular filtration rate.

$* P$ value $<0.05$ is statistically significant.

Table 3. Comparison of the frequency of HLA in the patients with diabetic nephropathy and the control group

\begin{tabular}{|c|c|c|c|}
\hline \multirow[b]{2}{*}{ HLA } & \multicolumn{2}{|c|}{ Groups } & \multirow[b]{2}{*}{$P$ value ${ }^{*}$} \\
\hline & $\begin{array}{c}\text { Patients with T2DM without diabetic } \\
\text { nephropathy (60 cases) }\end{array}$ & $\begin{array}{l}\text { Patients with T2DM and diabetic nephropathy } \\
\qquad \text { (60 cases) }\end{array}$ & \\
\hline A0201 & 5 (8.3 \%) & $6(10 \%)$ & 0.75 \\
\hline A0301 & $8(13.3 \%)$ & $8(13.3 \%)$ & 0.9 \\
\hline A0401 & 3 (5 \%) & 9 (15\%) & 0.07 \\
\hline A0501 & 5 (8.3 \%) & 4 (4.7 \%) & 0.73 \\
\hline B0201 & 7 (11.7 \%) & $8(13.3 \%)$ & 0.78 \\
\hline B0301 & $5(8.3 \%)$ & $5(8.3 \%)$ & 0.9 \\
\hline B0401 & 3 (5 \%) & 3 (5 \%) & 0.9 \\
\hline B0501 & 7 (11.7 \%) & $6(10 \%)$ & 0.77 \\
\hline
\end{tabular}

$* P$ value $<0.05$ is statistically significant.

group (healthy subjects) was reported (16). The reason for the lack of association between different levels of HLA in the two groups of the studied patients in this study can be due to differences in the characteristics of the two groups, such as demographic characteristics and lifestyle and even the geographical area, as in Laadhar et al (31), and Todd et al (32), demographic characteristics have been introduced as effective factors for different levels of HLA.

According to the results of this study, alleles of HLA-DQA ${ }^{*} 0401$ and HLA-DQA ${ }^{*} 0301$ and HLADQB $1 * 0201$ were $15 \%, 13.3 \%$ and $13.3 \%$ respectively in type 2 diabetes patients and diabetic nephropathy and in the non-diabetic nephropathy group, the highest rates were
$13.3 \%, 11.7 \%$ and $11.7 \%$, for alleles of HLA-DQA $1 * 0301$ and HLA-DQB1*0201 and HLA-DQB $1 * 0501$ respectively which is consistent with the study of Ma et al (16). In their study HLADQA1*0301, in diabetic nephropathy and the control group was $15.5 \%$ versus $8 \%(P<0.01)$, HLADQA ${ }^{*} 0501$ was $16.6 \%$ versus $8.5 \%(P<0.01)$, HLADQA ${ }^{*} 0302$ was $6.5 \%$ versus $13.5 \%(P<0.01)$ and HLA$\mathrm{DQB}^{*} 0501$ was $5.8 \%$ versus $14.5 \%(P<0.01)$. Since there was no significant relationship between different alleles in the present study, which is not consistent with the study of Ma et al (16), it seems that the rate of HLA alleles and the association between them in the two groups of patients depends on racial and ethnic characteristics of 


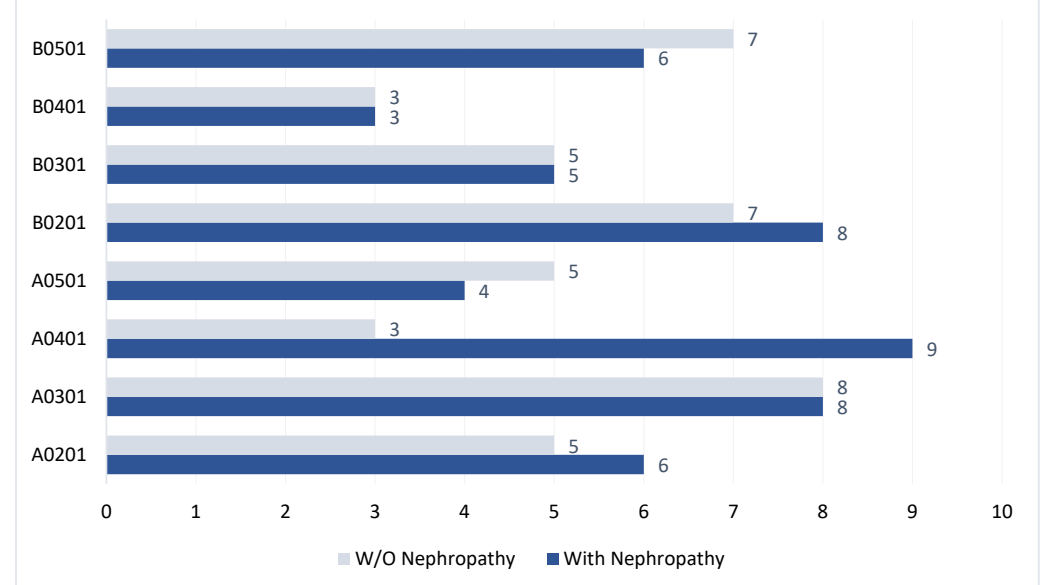

Figure 1. Comparison of the frequency of HLA in the patients with diabetic nephropathy and the control group.

each population. Few studies have been conducted on the relationship between T2DM and HLA, therefore this relationship is remaining unclear. However, in a study in Punjab, no relationship was reported between HLA-DQ and HLA-DR with type 2 diabetes (33), on the other hand type 2 diabetes was appreciably associated with HLADQA in Belgians (34). In Bahrain, relationship between type 2 diabetes with HLA-DQB1 and HLA-DRB1 was statistically significant (35). Differences in the results of this section, which have been reported in various studies, can be attributed to potential factors such as study design and sample size.

\section{Conclusion}

In this study, there was no statistically difference between the two groups regarding $\mathrm{HbAlc}$, fasting plasma glucose and body mass index. However, there was a significant difference between the groups in systolic and diastolic blood pressures, though no significant difference between different levels of HLA in the two groups of patients was detected. Researchers of this study consider the various factors such as demographic characteristics, lifestyle, geographic region, and race as factors influencing the relationship between diabetic nephropathy and type 2 human leukocyte antigen (DQ1-HLA II). Since this study is conducted in one region and one race and with limited population, it is suggested that future studies should be considered and the association between the mentioned variables with type 2 HLA should be considered.

\section{Limitation of the study}

Limited statistical population and the cost of the experiments studied were limitation of this study.

\section{Acknowledgments}

This article is based on Dr. Mahsa Mohammadi's thesis on internal medicine that it has been approved and sponsored by the Vice Chancellor for Research and Technology of
Kurdistan University of Medical Sciences [IR.MUK. REC.1397.111]. The authors would like to thank all patients and their family for help to perform this study.

\section{Authors' contribution}

All authors passed four criteria for authorship contribution based on recommendations of the International Committee of Medical Journal Editors. MM, MB and MSF conducted the research. MM and MR wrote the primary draft. MM and MB prepared the final paper. MSF and MR conducted the final check of the paper. All authors read and signed the final paper.

\section{Conflicts of interest}

The authors declare that they have no conflict of interest.

\section{Ethical issues}

The study was in accordance with the Declaration of Helsinki and all participants gave their informed consent to enter the study. The study was approved by the Research Committee and the Ethical Committee of the Kurdistan University of Medical Sciences (Ethics code\# IR.MUK.REC.1397.111). This study was extracted from the residential thesis by Mahsa Mohammadi at the department of internal medicine of this university. Moreover, ethical issues (including plagiarism, data fabrication, double publication) have been completely observed by the authors.

\section{Funding/Support}

This work was supported by the Vice Chancellor for Research and Technology of Kurdistan University of Medical Sciences.

\section{References}

1. Punthakee Z, Goldenberg R, Katz P. Definition, classification and diagnosis of diabetes, prediabetes and metabolic syndrome. Can J Diabetes. 2018;42 Suppl 1:S10-S15. doi: 
10.1016/j.jcjd.2017.

2. Guariguata L, Whiting DR, Hambleton I, Beagley J, Linnenkamp U, Shaw JE. Global estimates of diabetes prevalence for 2013 and projections for 2035. Diabetes Res Clin Pract. 2014;103:137-149. doi:10.1016/j. diabres.2013.11.002

3. Papatheodorou K, Papanas N, Banach M, Papazoglou D, Edmonds M. Complications of diabetes 2016. J Diabetes Res. 2016;2016:6989453. doi:10.1155/2016/6989453

4. Kautzky-Willer A, Harreiter J, Pacini G. Sex and gender differences in risk, pathophysiology and complications of type 2 diabetes mellitus. Endocr Rev. 2016;37:278-316. doi: 10.1210/er.2015-1137.

5. System URD. USRDS 2013 annual data report: atlas of chronic kidney disease and end-stage renal disease in the United States. National Institutes of Health, National Institute of Diabetes and Digestive; 2013.

6. Finne P, Groop P-H, Arffman M, Kervinen M, Helve J, Grönhagen-Riska C, et al. Cumulative risk of end-stage renal disease among patients with type 2 diabetes: a nationwide inception cohort study. Diabetes Care. 2019;42:539-44.

7. Zheng Y, Ley SH, Hu FB. Global aetiology and epidemiology of type 2 diabetes mellitus and its complications. Nat Rev Endocrinol. 2018 Feb;14:88-98. doi: 10.1038/ nrendo.2017.151.

8. Wu A, Kong N, De Leon F, Pan C, Tai T, Yeung V, et al. An alarmingly high prevalence of diabetic nephropathy in Asian type 2 diabetic patients: the MicroAlbuminuria Prevalence (MAP) Study. Diabetologia. 2005;48(1):17-26.

9. Bailey RA, Wang Y, Zhu V, Rupnow MF. Chronic kidney disease in US adults with type 2 diabetes: an updated national estimate of prevalence based on Kidney Disease: Improving Global Outcomes (KDIGO) staging. BMC Res Notes. 2014;7:415. doi:10.1186/1756-0500-7-415.

10. So W, Ma R, Ozaki R, Tong P, Ng M, Ho C, et al. Angiotensin-converting enzyme (ACE) inhibition in type 2, diabetic patients-interaction with ACE insertion/ deletion polymorphism. Kidney Int. 2006;69(8):1438-43.

11. Wu C-C, Sytwu H-K, Lu K-C, Lin Y-F. Role of T cells in type 2 diabetic nephropathy. xp Diabetes Res. 2011;2011:514738. doi: 10.1155/2011/514738.

12. Fernando MM, Stevens CR, Walsh EC, De Jager PL, Goyette P, Plenge RM, et al. Defining the role of the MHC in autoimmunity: a review and pooled analysis. PLoS genetics. 2008;4(4):e1000024.

13. Ražanskaitè-Virbickiené D, Danytė E, Žalinkevičius R. HLA-DRB $1 * 03$ as a risk factor for microalbuminuria in same duration of type 1 diabetes: a case control study. BMC Nephrol. 2016;17:38. doi: 10.1186/s12882-016-0252-4

14. Cordovado SK, Zhao Y, Warram JH, Gong H, Anderson $\mathrm{KL}$, Hendrix MM, et al. Nephropathy in type 1 diabetes is diminished in carriers of HLA-DRB $1 * 04$ : the genetics of kidneys in diabetes (GoKinD) study. Diabetes. 2008;57:51822.

15. Chowdhury T, Dyer P, Mijovic C, Dunger D, Barnett A, Bain S. Human leucocyte antigen and insulin gene regions and nephropathy in type I diabetes. Diabetologia. 1999;42:1017-20.

16. Ma ZJ, Sun P, Guo G, Zhang R, Chen LM. Association of the HLA-DQA1 and HLA-DQB1 Alleles in Type 2 Diabetes Mellitus and Diabetic Nephropathy in the Han Ethnicity of China. J Diabetes Res. 2013;2013:452537. doi:
$10.1155 / 2013 / 452537$.

17. American Diabetes Association. 2. Classification and diagnosis of diabetes. Diabetes Care. 2017;40:S11-S24.

18. Wei W, Xin X, Shao B, Zeng F, Love E, Wang B. The relationship between anthropometric indices and type 2 diabetes mellitus among adults in north-east China. Public Health Nutr. 2014;18:1675-83.

19. Zhou X, Ji L, Ran X, Su B, Ji Q, Pan Ch, Weng J, et al. Prevalence of obesity and its influence on achievement of cardiovascular therapeutic goals in Chinese type 2 diabetes patients: an analysis of the nationwide, cross-sectional 3B study. PLoS One. 2016;11:e0144179.doi: 10.1371/journal. pone.0144179.

20. Saleem Z, Saeed H, Abbas khan Z, Hassan Khan M, Hashmi F, Islam M, et al. Association of hypertension and dyslipidemia with increasing obesity in patients with type 2 diabetes mellitus. Brazilian Journal of Pharmaceutical Sciences. 2019;55:e18136.

21. Gaal L, Scheen A. Weight management in type 2 diabetes: current and emerging approaches to treatment. Diabetes Care. 2015;38:1161-72.

22. Seck T, Nauck M, Sheng D, Sunga S, Davies M, Stein P, et al. Safety and efficacy of treatment with sitagliptin or glipizide in patients with type 2 diabetes inadequately controlled on metformin: a 2-year study. Int J Clin Pract. 2010;64(5):562576. doi:10.1111/j.1742-1241.2010.02353.x.

23. Aghamohammadzadeh N, Najafipour F, Aliasgharzadeh A, Bahrami A, Niafar M, Mobasseri M, et al. Prevalency of diabetic nephropathy among type 2 diabetic patients. Journal of Gorgan University of Medical Sciences. 2009;11:62-66.

24. Safaei H, Amini M. Quality of control and treatment of blood pressure in type 2 diabetes patient with hypertension. Iranian Journal of Endocrinology and Metabolism. 2007;9:235-41.

25. Duggirala MK, Cuddihy RM, Cuddihy M-T, Naessens JM, Cha SS, Mandrekar JN, et al. Predictors of blood pressure control in patients with diabetes and hypertension seen in primary care clinics. Am J Hypertens. 2005;18:833-8. doi: 10.1016/j.amjhyper.2004.12.016.

26. Farahandi H, Mohebbi B, Tol A, Sadeghi R, Nori Jaliani K. The impacts of blended educational intervention program on blood pressure control and promoting HbAlc among type 2 diabetic patients with hypertension. Razi Journal of Medical Sciences. 2015;22:88-96.

27. Rahimi M, Niromand E, Rezaii M. The Relationship between Fasting and Postprandial Blood Glucose with HbA1C in Type 2 Diabetes. ZUMS Journal. 2009;17:45-53.

28. Glasgow RE, Hampson SE, Strycker LA, Ruggiero L. Personal-model beliefs and social-environmental barriers related to diabetes self-management. Diabetes Care. 1997;20:556-61.

29. Quiroz-Mercado H, Sanchez-Noguera C, Fromow-Guerra J, Salazar-Teran N, Martinez-Castellanos M, VelezMontoya R, et al. Relationship Between HLA Class II Alleles and Proliferative Diabetic Retinopathy in Mexican Patients With Type 2 Diabetes Mellitus (T2D). Investigative Ophthalmology \& Visual Science. 2008;49(13):2149.

30. Marzban A, Kiani J, Hajilooi M, Rezaei H, Kahramfar Z, Solgi G. HLA class II alleles and risk for peripheral neuropathy in type 2 diabetes patients. Neural Regen Res. 2016;11:1839-44. doi: 10.4103/1673-5374.194756. 
31. Laadhar L, Harzallah F, Zitouni M, Kallel-Sellami M, Fekih M, Kaabachi N, et al. HLA class II alleles susceptibility markers of type 1 diabetes fail to specify phenotypes of ketosis-prone diabetes in adult Tunisian patients. Exp Diabetes Res. 2011;2011:964160. doi: 10.1155/2011/964160.

32. Todd JA, Bell JI, McDevitt HO. HLA-DQ $\beta$ gene contributes to susceptibility and resistance to insulin-dependent diabetes mellitus. Nature. 1987;329:599.

33. Hitman G, Karir P, Mohan V, Rao P, Kohner E, Levy J, et al. A Genetic Analysis of Type 2 (Non-insulin-dependent) Diabetes Mellitus in Punjabi Sikhs and British Caucasoid
Patients. Diabet Med. 1987;4:526-30. doi: 10.1111/j.14645491.1987.tb00923.x.

34. Ghabanbasani MZ, Spaepen M, Buyse I, Legius E, Decorte $\mathrm{R}, \mathrm{Bex} \mathrm{M}$, et al. Increased and decreased relative risk for noninsulin-dependent diabetes mellitus conferred by HLA class II and by CD4 alleles. Clin Genet. 1995;47:225-30.

35. Motala AA, Busson M, Al-Harbi EM, Khuzam MA, AlOmari EM, Arekat MR, et al. Susceptible and protective human leukocyte antigen class II alleles and haplotypes in Bahraini type 2 (non-insulin-dependent) diabetes mellitus patients. Clin Diagn Lab Immunol. 2005;12:213-7.

Copyright $\odot 2021$ The Author(s); Published by Nickan Research Institute. This is an open-access article distributed under the terms of the Creative Commons Attribution License (http://creativecommons.org/licenses/by/4.0), which permits unrestricted use, distribution, and reproduction in any medium, provided the original work is properly cited. 